\title{
Studies on the Effect of Zinc Chloride Mixing on Bisthiourea Cadmium Chloride Crystals
}

\author{
R. S. Sundararajan, M. Senthilkumar, C. Ramachandraraja* \\ Department of Physics, Government Arts College (Autonomous), Kumbakonam, India \\ Email: *crraja_phy@yahoo.com
}

Received September 11, 2013; revised October 23, 2013; accepted October 30, 2013

Copyright (C) 2013 R. S. Sundararajan et al. This is an open access article distributed under the Creative Commons Attribution License, which permits unrestricted use, distribution, and reproduction in any medium, provided the original work is properly cited.

\begin{abstract}
Nonlinear optical Zinc mixed bisthiourea Cadmium chloride (BTCC) crystals were synthesized and grown by slow evaporation method. The FTIR analysis reveals that the $\mathrm{C}-\mathrm{N}$ stretching frequencies of thiourea are shifted towards the higher frequencies for pure and Zinc mixed BTCC and the $\mathrm{C}=\mathrm{S}$ stretching frequencies are shifted towards the lower frequencies for pure and Zinc mixed BTCC crystals. These observations suggest that the metals coordinate with thiourea through sulphur. UV-Vis-NIR spectra were recorded to study the optical transparency of the grown crystals. The lower cutoff wavelength is observed at $233 \mathrm{~nm}$ for the pure BTCC crystals. There is no comparable change in the lower cutoff wavelength for the Zinc mixed BTCC crystals. The Nonlinear Optical (NLO) efficiency of the pure BTCC crystal decreases with the increase percentage mixing of Zinc. The SHG output for BTCC mixed with $1 \%$ zinc chloride is almost 9 times greater than the SHG output obtained for Pottasium Dihydrogen Phosphate (KDP) crystal. Vicker's microhardness test done on the experimental crystals proves their greater physical strength.
\end{abstract}

Keywords: Zinc; BTCC; Crystals; Nonlinear Optical (NLO)

\section{Introduction}

Nonlinear optical (NLO) materials play an important role in nonlinear optics, optical communication, optical switching, optical disk data storage, laser fusion reactions, optical rectifications and in particular they have a great impact on information technology and industrial applications [1-6]. The approach of combining the high nonlinear optical coefficient of the organic molecules with the excellent physical properties of the inorganics was found to be extremely successful in the recent past [7-11]. Thiourea, which is centrosymmetric, yields excellent noncentrosymmetric materials. Zinc chloride mixed bisthiourea cadmium chloride crystals were synthesized and grown by slow evaporation method and identified as the useful crystals for nonlinear optical applications.

In this present work, growth of zinc chloride mixed BTCC crystals and their characterization through XRD, FTIR, UVVis-NIR, SHG and micro hardness analysis are discussed.

\section{Experimental Growth of Pure BTCC Crystals}

BTCC crystal was synthesized by dissolving AR grade

${ }^{*}$ Corresponding author. thiourea and AR grade cadmium chloride in the molar ratio 2:1 in distilled water. The saturated solution of cadmium chloride is slowly added to the saturated solution of thiourea. This is stirred well to get a clear solution. Pure BTCC crystal was synthesized according to the reaction,

$$
2\left[\mathrm{CS}\left(\mathrm{NH}_{2}\right)_{2}\right]+\mathrm{CdCl}_{2} \rightarrow \mathrm{Cd}\left[\mathrm{CS}\left(\mathrm{NH}_{2}\right)_{2}\right]_{2} \mathrm{Cl}_{2}
$$

The solution was purified by repeated filteration. The saturated solution was kept in a beaker covered with polythene paper. For slow evaporation 6 or 7 holes are made in the polythene paper. Then the solution is left undisturbed in a constant temperature bath (CTB) kept at a temperature of $35^{\circ} \mathrm{C}$ with an accuracy of $\pm 0.1^{\circ} \mathrm{C}$. As a result of slow evaporation, after 75 days colorless and transparent pure BTCC crystals were obtained (Figure 1).

The same procedure was followed to grow zinc chloride mixed BTCC crystals.

\section{Result and Discussion}

\subsection{Single Crystal XRD Analysis}

The lattice dimensions and the crystal system have been 


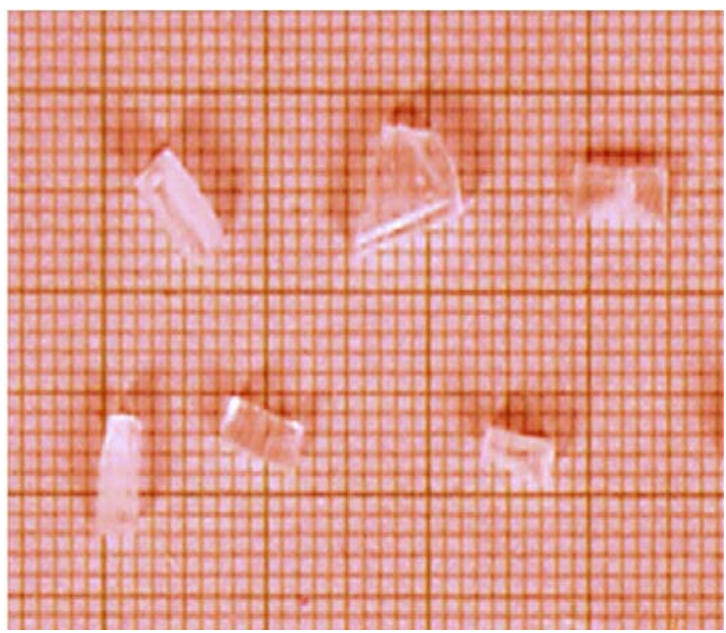

Figure 1. Photograph of pure BTCC Crystals.

determined from the single X-ray diffraction analysis (Model: ENRAF NONIUS CAD 4). The determined unit cell parameters and the observed crystal system are reported in the Table 1.

\subsection{Powder XRD Analysis}

Powder XRD analysis of the grown zinc chloride mixed BTCC crystals have been carried out using Rich Siefert diffractometer with $\mathrm{Cu} \mathrm{Ka} \lambda=1.5406 \mathrm{~A}^{\circ}$ radiation on crushed powder of zinc chloride mixed BTCC crystals. The recorded powder X-ray patterns are shown in Figure 2. The differences in amplitude of the peak can be attributed to the difference in grain size and orientation of the powdered grains of the experimental crystals. The observed diffraction is indexed by Rietveld index software package. The lattice parameters calculated by Reitveld software package are tabulated in Table 2. The data obtained by powder X-ray diffraction are in good agreement with the single crystal XRD data.

\subsection{Fourier Transform Infrared Spectroscopy (FTIR) Analysis}

The FTIR spectroscopy studies were used to analyze the presence of functional groups in synthesized compound. The FTIR spectrums of pure BTCC and zinc chloride mixed BTCC were recorded using Perkin Elmer spectrum FTIR spectrometer by $\mathrm{KBr}$ pellet technique in the range $4000-400 \mathrm{~cm}^{-1}$ (Figures 3(a)-(d)). The characteristic vibrational frequencies of the functional groups of pure BTCC and zinc chloride mixed BTCC have been compared with thiourea. The comparison of characteristic vibrational frequencies is given in Table 3.

In the FTIR spectra, the NH stretching vibrational bands were observed around $3383 \mathrm{~cm}^{-1}, 3297 \mathrm{~cm}^{-1}$ and $3200 \mathrm{~cm}^{-1}$. These bands were shifted to higher wave number region when compared to that of the free ligand.

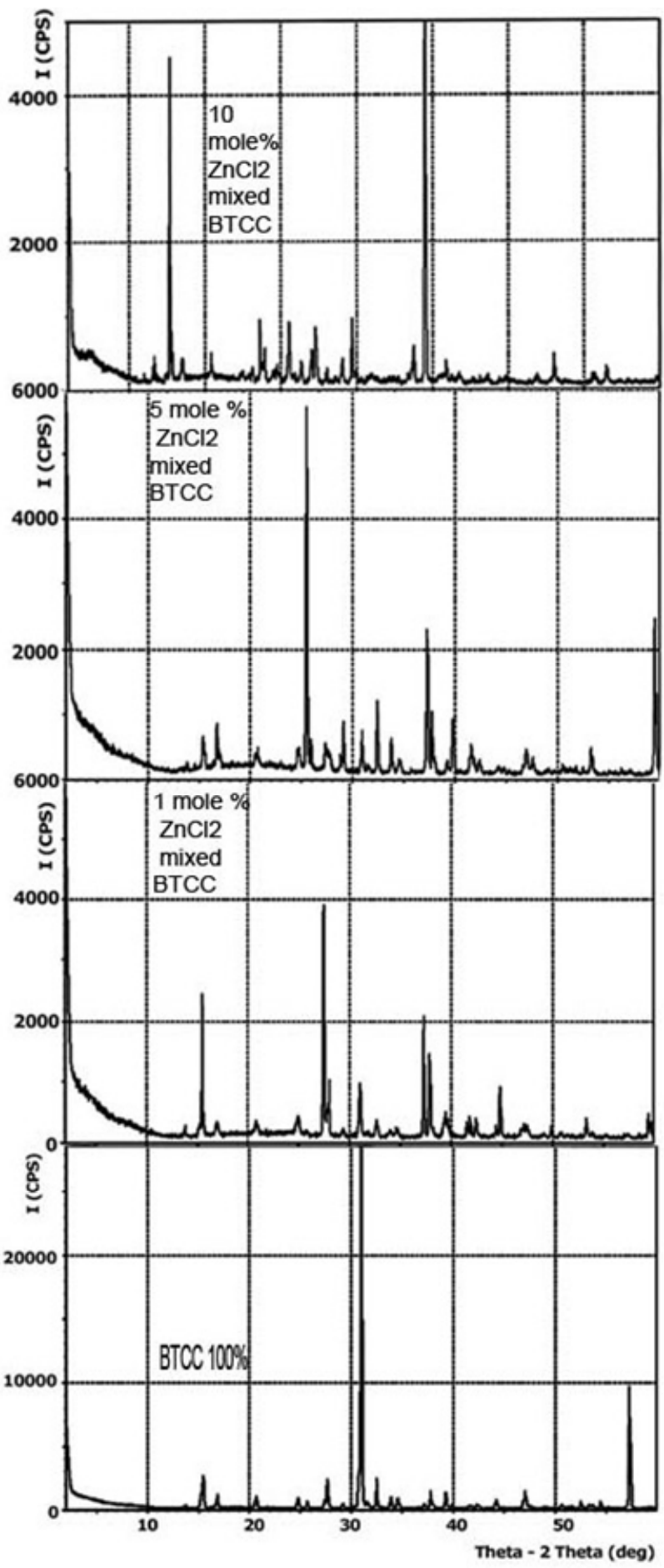

Figure 2. Powder XRD pattern of BTCC and $\mathrm{ZnCl}_{2}$ mixed BTCC.

This shift may be due to the increases in the polar character of thiourea molecule because of the formation of $\mathrm{s}$ $\rightarrow \mathrm{m}$ bands in pure and zinc chloride mixed $\mathrm{Cd}[\mathrm{Tu}]_{2} \mathrm{Cl}_{2}$ complex.

The bands observed around $1620 \mathrm{~cm}^{-1}$ in the investigated crystals correspond to $\mathrm{NH}_{2}$ bending vibration. The 
Table 1. Single crystal XRD results of the grown crystals.

\begin{tabular}{|c|c|c|c|c|c|}
\hline Sl. No. & Crystal name & Axial lengths of unit cell (a, $b$ and $c)$ & $\begin{array}{l}\text { Inter axial angles } \\
\qquad(\alpha, \beta \text { and } \gamma)\end{array}$ & Volume & Crystal system \\
\hline 1 & BTCC $100 \%$ & $\begin{array}{c}\mathrm{a}=5.804 \AA \\
\mathrm{b}=6.463 \AA ; \mathrm{c}=13.099 \AA\end{array}$ & $\alpha=\beta=\gamma=90^{\circ}$ & $491.3(4) \AA^{3}$ & Orthorhombic \\
\hline 2 & 1 mole $\% \mathrm{ZnCl}_{2}$ mixed BTCC & $\begin{array}{c}\mathrm{a}=5.805 \AA \\
\mathrm{b}=6.468 \AA ; \mathrm{c}=13.155 \AA\end{array}$ & $\alpha=\beta=\gamma=90^{\circ}$ & $492.5(3) \AA^{3}$ & Orthorhombic \\
\hline 3 & 5 mole $\% \mathrm{ZnCl}_{2}$ mixed $\mathrm{BTCC}$ & $\begin{array}{c}\mathrm{a}=5.827 \AA \\
\mathrm{b}=6.477 \AA ; \mathrm{c}=13.112 \AA\end{array}$ & $\alpha=\beta=\gamma=90^{\circ}$ & $494.8(5) \AA^{3}$ & Orthorhombic \\
\hline 4 & 10 mole $\% \mathrm{ZnCl}_{2}$ mixed BTCC & $\begin{array}{c}\mathrm{a}=5.822 \AA \\
\mathrm{b}=6.474 \AA ; \mathrm{c}=13.097 \AA\end{array}$ & $\alpha=\beta=\gamma=90^{\circ}$ & $493.7(3) \AA^{3}$ & Orthorhombic \\
\hline
\end{tabular}

BTCC—Bisthiourea cadmium chloride; BTZC—Bisthiourea zinc chloride.

Table 2. Powder XRD results of the grown crystals.

\begin{tabular}{|c|c|c|c|c|c|}
\hline S1. No. & Crystal name & $\begin{array}{l}\text { Observed a,b,c values by } \\
\text { single XRD analysis }\end{array}$ & $\begin{array}{c}\text { Calculated a,b,c values by } \\
\text { powder XRD analysis }\end{array}$ & $\begin{array}{l}\text { Observed volume by } \\
\text { single XRD analysis }\end{array}$ & $\begin{array}{l}\text { Calculated volume by } \\
\text { powder XRD analysis }\end{array}$ \\
\hline 1 & BTCC $100 \%$ & $\begin{array}{c}\mathrm{a}=5.804 \AA ; \mathrm{b}=6.463 \AA \\
\mathrm{c}=13.099 \AA\end{array}$ & $\begin{array}{c}\mathrm{a}=5.794 \AA \\
\mathrm{b}=6.461 \AA ; \mathrm{c}=13.139 \AA\end{array}$ & $491.3(4) \AA^{3}$ & $491.91(3) \AA^{3}$ \\
\hline 2 & 1 mole $\% \mathrm{ZnCl}_{2}$ mixed BTCC & $\begin{array}{c}\mathrm{a}=5.805 \AA ; \mathrm{b}=6.468 \AA \\
\mathrm{c}=13.155 \AA\end{array}$ & $\begin{array}{c}\mathrm{a}=5.812 \AA \\
\mathrm{b}=6.466 \AA ; \mathrm{c}=13.161 \AA\end{array}$ & $492.5(3) \AA^{3}$ & $494.62(3) \AA^{3}$ \\
\hline 3 & 5 mole $\% \mathrm{ZnCl}_{2}$ mixed BTCC & $\begin{array}{c}\mathrm{a}=5.827 \AA ; \mathrm{b}=6.477 \AA \\
\mathrm{c}=13.112 \AA\end{array}$ & $\begin{array}{c}\mathrm{a}=5.814 \AA \\
\mathrm{b}=6.484 \AA ; \mathrm{c}=13.105 \AA\end{array}$ & $494.8(5) \AA^{3}$ & $494.15(3) \AA^{3}$ \\
\hline 4 & 10 mole $\% \mathrm{ZnCl}_{2}$ mixed BTCC & $\begin{array}{c}\mathrm{a}=5.822 \AA ; \mathrm{b}=6.474 \AA \\
\mathrm{c}=13.097 \AA\end{array}$ & $\begin{array}{c}\mathrm{a}=5.819 \AA \\
\mathrm{b}=6.474 \AA ; \mathrm{c}=13.099 \AA\end{array}$ & $493.7(3) \AA^{3}$ & $493.50(3) \AA^{3}$ \\
\hline
\end{tabular}

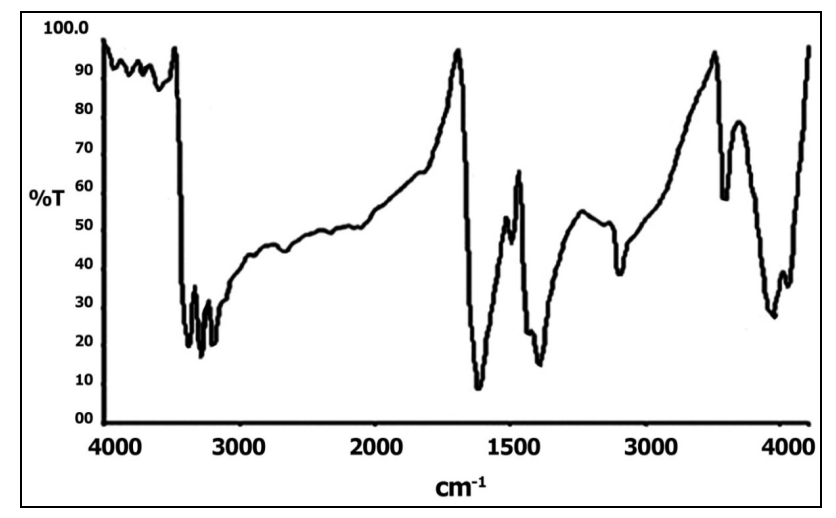

(a)

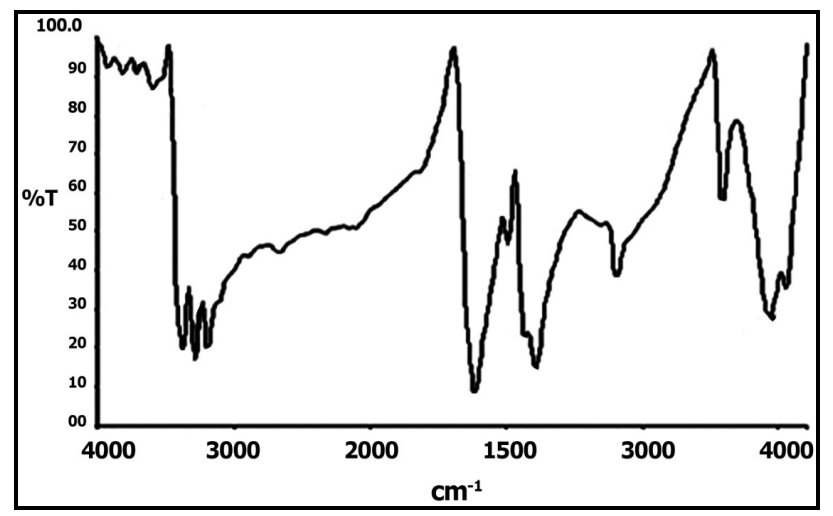

(c)

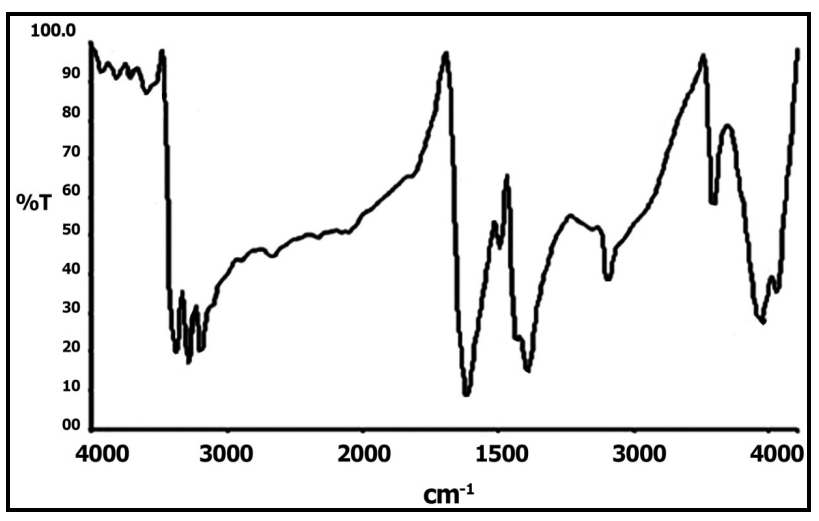

(b)

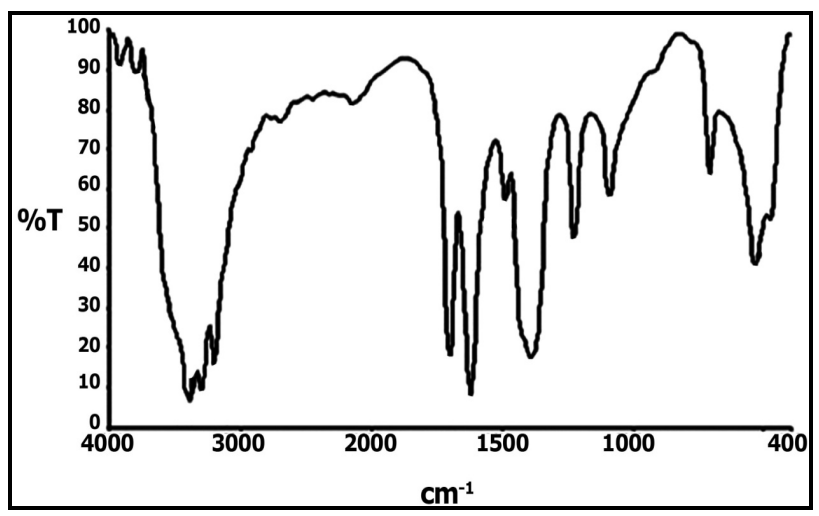

(d)

Figure 3. (a) FTIR Spectrum of BTCC; (b) FTIR Spectrum of 1 mole \%. $\mathrm{ZnCl}_{2}$ mixed BTCC; (c) FTIR Spectrum of 5 mole $\% \mathrm{ZnCl}_{2}$ mixed BTCC; (d): FTIR Spectrum of 10 mole \%. $\mathrm{ZnCl}_{2}$ mixed BTCC. 
Table 3. The comparison of characteristic vibrational frequencies.

\begin{tabular}{ccccccc}
\hline Thiourea & $\begin{array}{c}\text { Pure BTCC } \\
\left(\mathrm{cm}^{-1}\right)\end{array}$ & $\begin{array}{c}\text { 1 mole \% zinc chloride } \\
\text { mixed BTCC }\left(\mathrm{cm}^{-1}\right)\end{array}$ & $\begin{array}{c}\text { 5 mole \% zinc chloride } \\
\text { mixed BTCC }\left(\mathrm{cm}^{-1}\right)\end{array}$ & $\begin{array}{c}\text { 10 mole \% zinc chloride } \\
\text { mixed BTCC }\left(\mathrm{cm}^{-1}\right)\end{array}$ & $\begin{array}{c}\text { Pure BTZC } \\
\left(\mathrm{cm}^{-1}\right)\end{array}$ & Assignments \\
\hline 494.12 & 474.32 & 473.89 & 471.59 & 478.66 & 474.89 & Asymmetric NCS bending \\
730.07 & 711.10 & 710.34 & 710.77 & 712.90 & 711.85 & C-N symmetric stretching \\
1082.18 & 1095.19 & 1095.46 & 1095.96 & 1092.18 & 1098.25 & NH $H_{2}$ rocking \\
1414.23 & 1393.26 & 1392.48 & 1394.42 & 1393.69 & 1402.81 & $\mathrm{C}=\mathrm{S}$ asymmetric Stretching \\
1477.31 & 1494.04 & 1493.88 & 1493.48 & 1489.55 & 1494.28 & $\mathrm{C}-\mathrm{N}$ asymmetric stretching \\
1620.19 & 1615.31 & 1615.73 & 1614.32 & 1623.16 & 1623.48 & NH $H_{2}$ asymmetric Bending \\
3177.22 & 3194.81 & 3195.06 & 3195.78 & 3202.09 & 3200.62 & N-H stretching \\
3279.43 & 3281.14 & 3281.59 & 3281.63 & 3295.24 & 3297.59 & N-H stretching \\
3380.17 & 3387.96 & 3387.22 & 3388.22 & 3395.09 & 3383.79 & N-H stretching \\
\hline
\end{tabular}

bands observed around $1494 \mathrm{~cm}^{-1}$ were identified as the N-C-N stretching vibration. The bands observed around $1402 \mathrm{~cm}^{-1}$ in the pure and zinc chloride mixed $\mathrm{Cd}\left[\mathrm{Tu}_{2}\right] \mathrm{Cl}_{2}$ crystals correspond to $\mathrm{C}=\mathrm{S}$ stretching vibration. The bands for $\mathrm{NH}_{2}$ rocking vibration in the grown crystals were observed around $1098 \mathrm{~cm}^{-1}$. The symmetric $\mathrm{C}=\mathrm{S}$ stretching was observed near $711 \mathrm{~cm}^{-1}$. The IR band for N-C-N bending vibration was observed around $474 \mathrm{~cm}^{-1}$.

The standard IR bands of thiourea and that obtained for pure and zinc chloride mixed $\mathrm{Cd}\left[\mathrm{TU}_{2}\right] \mathrm{Cl}_{2}$ crystal are compared along with their assignments and are presented in Table 3. It is found that the $\mathrm{NH}_{2}$ rocking and C-N stretching (1082 and $1477 \mathrm{~cm}^{-1}$ ) bands of thiourea are shifted to higher frequencies of pure and zinc chloride mixed BTCC crystals. Also the $\mathrm{C}=\mathrm{S}$ stretching bands of thiourea (1414 and $730 \mathrm{~cm}^{-1}$ ) are shifted to lower frequencies of pure and zinc chloride mixed BTCC crystals. These results reveal that the metals coordinate with thiourea through sulphur [12].

\subsection{UV-Vis-NIR Analysis}

Optical transmission spectra of pure and zinc chloride mixed BTCC crystals have been measured by adopting Cary 500 scan spectrophotometer. The transmission spec trum was recorded in the range from $190 \mathrm{~nm}-1100 \mathrm{~nm}$. UV-Vis-NIR spectrum was recorded to study the optical transparency of the grown pure and zinc chloride mixed BTCC crystals (Figures 4(a)-(d)). The grown crystals are transparent in the wavelength region from $250 \mathrm{~nm}$ to $1100 \mathrm{~nm}$. The lower cut off wavelength is observed at $250 \mathrm{~nm}$ for the pure BTCC crystals. When the 1 mole \% zinc chloride mixed with BTCC, there is no change in the lower cut off wavelength. Likewise the increasing percentage of zinc mixed with BTCC crystals, there is no comparable change in the lower cut off wavelength. The pure and zinc mixed BTCC crystals are having good transparency in the entire visible region.

\subsection{Second Harmonic Generation Studies}

The second harmonic generation test was carried out by classical powder method developed by Kurtz and Perry. It is an important and popular tool to evaluate the conversion efficiency of NLO materials. The fundamental beam of $1064 \mathrm{~nm}$ from Q switched Nd: YAG laser was used to test the second harmonic generation (SHG) property of pure BTCC and zinc chloride mixed BTCC crystals. Pulse energy $2.9 \mathrm{~mJ} / \mathrm{pulse}$ and pulse width $8 \mathrm{~ns}$ with a repetition rate of $10 \mathrm{~Hz}$ were used. The photo multiplier tube (Hamahatsu R2059) was used as detector and 90 degree geometry was employed. The input laser beam was passed through an IR detector and then directed on the microcrystalline powdered sample packed in a capillary tube. The SHG signal generated in the sample was confirmed from the emission of green light from the sample [13]. The SHG output of pure BTCC crystal was $98 \mathrm{mV}$. The SHG output of BTCC mixed with 1 mole \% of zinc chloride was decreased to $91 \mathrm{mv}$. Likewise the SHG output of pure BTCC crystal is gradually decreased with the increased percentage mixing of zinc chloride (Table 4). This may be due to the lesser atomic weight of zinc when compared with cadmium since the decrease in the atomic weight reduces the pulling effect on $\mathrm{C}=\mathrm{S}$ band which results in absence of centre of symmetry [14].

\subsection{Micro Hardness}

Vicker's micro hardness test was carried out for pure BTCC crystals and also zinc chloride mixed BTCC crystals. The results tabulated (Table 5) shows that all the experimental crystals have great physical strength which is well established by the increase in the hardness value with increase in the load.

\section{Conclusion}

The good nonlinear optical quality, pure bisthiourea cadmium chloride and zinc chloride mixed BTCC crys- 


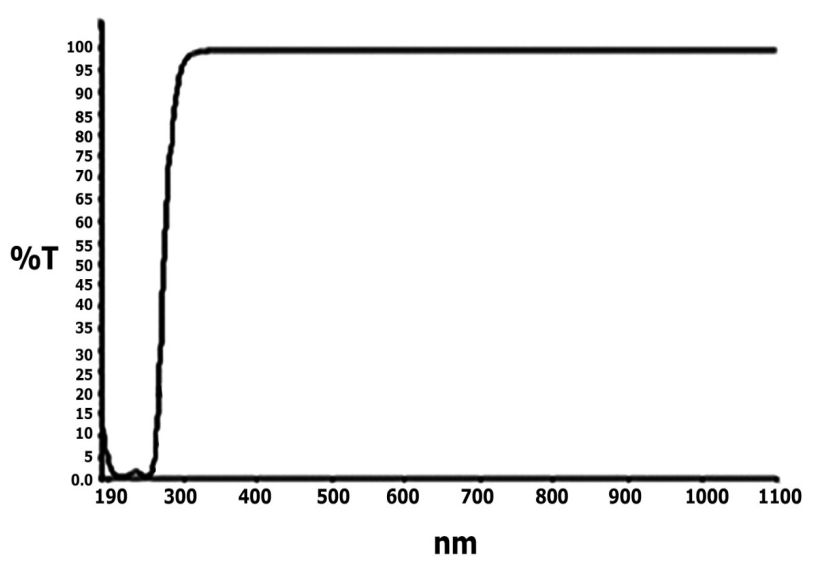

(a)

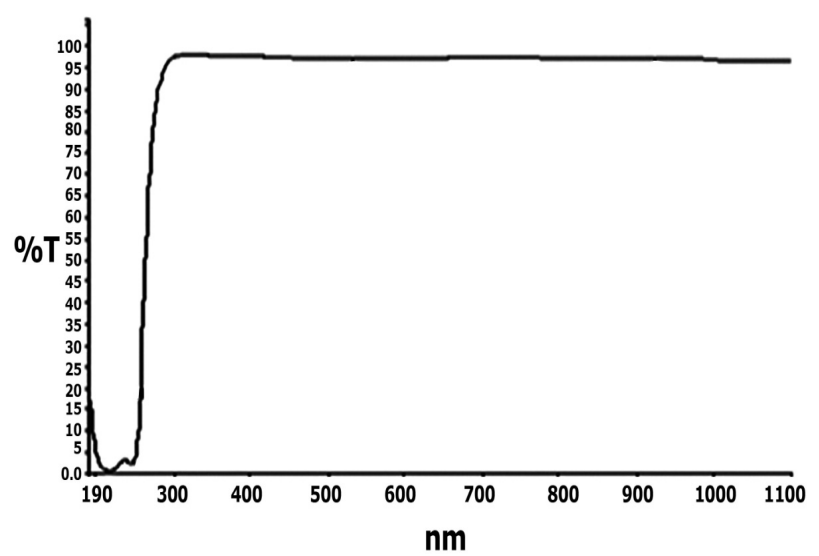

(c)

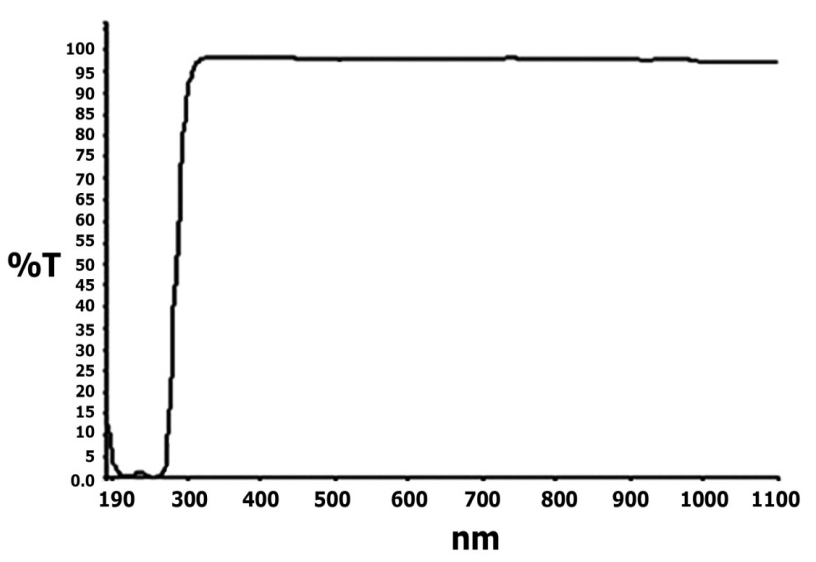

(b)

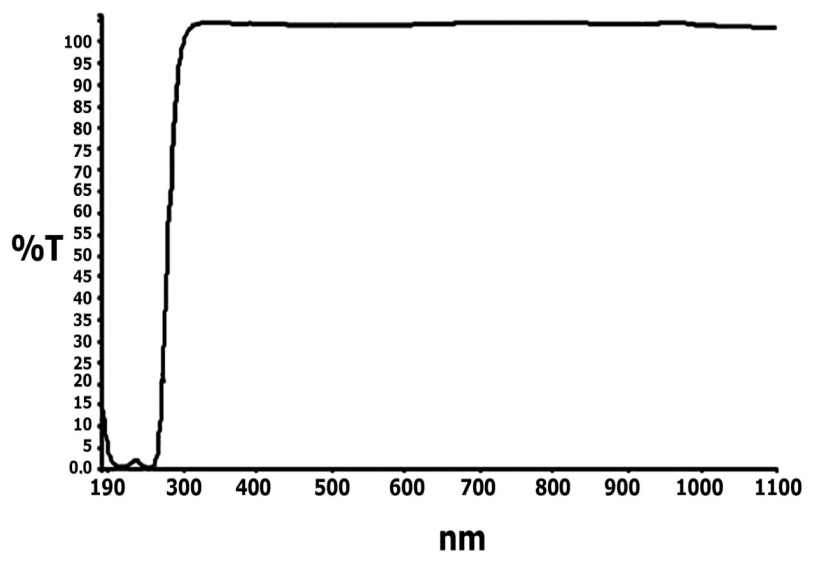

(d)

Figure 4. (a) UV-Vis-NIR spectrum of BTCC; (b) UV-Vis-NIR spectrum of 1 mole $\% \mathrm{ZnCl}_{2}$ mixed BTCC; (c) UV-Vis-NIR spectrum of 5 mole \% $\mathrm{ZnCl}_{2}$ mixed BTCC; (d) UV-Vis-NIR spectrum of 10 mole $\% \mathrm{ZnCl}_{2}$ mixed BTCC.

Table 4. NLO efficiency results.

\begin{tabular}{cc}
\hline Crystal & NLO efficiency in mv \\
\hline Pure BTCC & 98 \\
1 mole $\% \mathrm{ZnCl}_{2}$ mixed BTCC & 91 \\
5 mole $\% \mathrm{ZnCl}_{2}$ mixed BTCC & 90 \\
$10 \mathrm{~mole}_{\mathrm{Z} \mathrm{ZnCl}_{2} \text { mixed BTCC }}$ & 76 \\
$\mathrm{KDP}$ & 11 \\
Urea & 104 \\
\hline
\end{tabular}

Table 5. Micro hardness results of the grown crystals.

\begin{tabular}{cccccc}
\hline Load & Pure BTCC & 1 mole $\% \mathrm{ZnCl}_{2}$ mixed BTCC & 5 mole $\% \mathrm{ZnCl}_{2}$ mixed BTCC & 10 mole $\% \mathrm{ZnCl}_{2} \mathrm{mixed} \mathrm{BTCC}$ \\
\hline grams & $\mathbf{H V}$ & $\mathbf{H V}$ & $\mathbf{H V}$ & $\mathbf{H V}$ \\
25 & 41.4 & 15.6 & 22.6 & 35.1 \\
50 & 58.2 & 28.1 & 35.0 & 54.6 \\
100 & 74.4 & 48.7 & 55.7 & 83.8 \\
\hline
\end{tabular}

tals were grown by slow evaporation method. The grown crystals were characterized by single crystal XRD, powder XRD, FTIR analysis, UV-Vis-NIR analysis, second harmonic generation and Vicker's micro hardness studies. The lattice parameters obtained from single crystal XRD matches with that of lattice parameters were calculated 
from powder XRD. The presence of functional groups and the coordination of metal ions to thiourea through sulphur were conformed by FTIR analysis. The UVVis-NIR analysis reveals that the pure and zinc chloride mixed BTCC crystals are having good transparency in the entire visible region. The nonlinear optical (NLO) efficiency of the pure and zinc chloride mixed BTCC crystals was determined by the second harmonic generation studies. The increasing percentage of zinc chloride in pure BTCC crystals causes a decrease in its nonlinear optical efficiency. The results of Vicker's micro hardness studies reveal that all the experimental crystals have greater physical strength.

\section{Acknowledgements}

The authors wish to thank St.Joseph's College, Trichy-2, SAIF, IIT Chennai-36, I.I.Sc., Bangalore and Madurai Kamaraj University, Madurai for the spectral facilities rendered. One of the authors, Dr. C. Ramachandraraja wishes to thank UGC, New Delhi, Government of India for granting a minor research project to carry out this research work.

\section{REFERENCES}

[1] S. Chenthamarai, D. Jayaraman, C. Subramanian and P. Ramasamy, "Mechanical and Optical Studies on Pure and Nitro Doped 4-Hydroxyacetophenone," Materials Letters, Vol. 47, No. 4-5, 2001, pp. 247-251. http://dx.doi.org/10.1016/S0167-577X(00)00242-1

[2] K. Ambujam, K. Rajarajan, S. Selvakumar, A. Joseph and P. Sagayaraj, "Growth and Characterization of a Novel NLO Crystal Bis-Glycine Hydrogen Chloride (BGHC)," Journal of Crystal Growth, Vol. 286, No. 2, 2006, pp. 440-444. http://dx.doi.org/10.1016/j.jcrysgro.2005.10.013

[3] S. S. Hussaini, N. R. Dhumane, G. Rabbani, P. Karmuse, V. G. Dongre and M. D. Shirsat, "Growth and High Frequency Dielectric Study of Pure and Thiourea Doped KDP Crystals," Crystal Research and Technology, Vol. 42, No. 11, 2007, pp. 1110-1116. http://dx.doi.org/10.1002/crat.200710929

[4] S. S. Hussaini, N. R. Dhumane, V. G. Dongre, P. Karmuse, P. Ghughare and M. D. Shirsat, "Effect of Glycine on the Optical Properties of Zinc Thiourea Chloride (ZTC) Single Crystal," Optoelectronics and Advanced Materials-Rapid Communications, Vol. 2, 2008, pp. 108-112.

[5] V. Kannan, N. P. Rajesh, R. Bairava Ganesh and P. Ramasamy, "Growth and Characterization of BisthioureaZinc Acetate, a New Nonlinear Optical Material," Jour- nal of Crystal Growth, Vol. 269, No. 2-4, 2004, pp. 565569. http://dx.doi.org/10.1016/j.jcrysgro.2004.05.051

[6] K. Meera, R. Muralidharan, R. Dhanasekaran, P. Manyum and P. Ramasamy, "Growth of Nonlinear Optical Material: L-Arginine Hydrochloride and Its Characterisation," Journal of Crystal Growth, Vol. 263, No. 1-4, 2004, pp. 510-516. http://dx.doi.org/10.1016/j.jcrysgro.2003.11.093

[7] M.-H. Jiang and Q. Fang, "Organic and Semiorganic Nonlinear Optical Materials," Advanced Materials, Vol. 11, No. 13, 1999, pp. 1147-1151. http://dx.doi.org/10.1002/(SICI)1521-4095(199909)11:13 $<1147::$ AID-ADMA1147>3.0.CO;2-H

[8] J. Ramajothi, S. Dhanushkodi and K. Nagarajan, "Crystal Growth, Thermal, Optical and Microhardness Studies of Tris (Thiourea) Zinc Sulphate-A Semiorganic NLO Material," Crystal Research and Technology, Vol. 39, No. 5, 2004, pp. 414-420. http://dx.doi.org/10.1002/crat.200310204

[9] S. Ariponnammal, S. Radhika, R. Selva and N. Victor Jeya, "High Pressure Electrical Resistivity Study on Nonlinear Single Crystal Zinc Thiourea Sulphate (ZTS)," Crystal Research and Technology, Vol. 40, No. 8, 2005, pp. 786-788. http://dx.doi.org/10.1002/crat.200410432

[10] M. J. Rosker, P. Cunningham, M. D. Ewbank, H. O. Marcy, F. R. Vachss, L. F. Warren, R. Gappinger and R. Borwick, "Salt-Based Approach for Frequency Conversion Materials," Pure and Applied Optics, Vol. 5, No. 5, 1996, p. 667.

http://dx.doi.org/10.1088/0963-9659/5/5/020

[11] K. Selvaraju, R. Valluvan, K. Kirubavathi and S. Kumararaman, "L-Cystine Hydrochloride: A Novel Semi-Organic Nonlinear Optical Material for Optical Devices," Optics Communications, Vol. 269, No. 1, 2007, pp. 230234. http://dx.doi.org/10.1016/j.optcom.2006.07.075

[12] S. Selvasekarapandian, K. Vivekanandan, P. Kolandaivel and T. K. Gundurao, "Vibrational Studies of Bis(thiourea) Cadmium Chloride and Tris(thiourea) Zinc Sulphate Semiorganic Non-Linear Optical Crystals," Crystal Research and Technology, Vol. 32, No. 2, 19997, pp. 299 309.

[13] S. K. Kurtz and T. T. Perry, "A Powder Technique for the Evaluation of Nonlinear Optical Materials," Journal of Applied Physics, Vol. 39, No. 8, 1968, p. 3798. http://dx.doi.org/10.1063/1.1656857

[14] R. Mohankumar, D. Rajanbabu, D. Jayaraman, R. Jayavel and K. Kitamura, "Studies on the Growth Aspects of SemiOrganic 1-Alanine Acetate: A Promising NLO Crystal," Journal of Crystal Growth, Vol. 275, 2005, pp. 19351939. 